\title{
Optimization of Physical and Imaging Properties of Flat Bread Enriched with Quinoa Flour
}

\author{
Shima Jaldani ${ }^{1}$, Behzad Nasehi ${ }^{1,2}$, Hasan Barzegar ${ }^{1}$, Niazali Sepahvand ${ }^{3}$ \\ 1- Department of Food Technology, Khuzestan Agricultural Sciences and Natural Resources University, Iran \\ 2- Department of Food Technology, Payame Noor University (PNU), Iran \\ 3- Faculty Member of Research Institute Sapling and Seed Modification in Karaj, Iran
}

Background and Objectives: Flat breads are the most consumed bread in Iran. Barbari one of the popular ones, is traditional flat leavened Iranian bread and one of the most popular breads consumed in Iran and some other countries in the Middle East.

Materials and Methods: The aim of this study was to evaluate the effect of substitution of wheat flour by whole quinoa flour (0-15\% substitution) and xanthan gum (0-1.5\%) on quality properties of Barbari bread. The effects of whole quinoa flour and xanthan gum additions on bread preparation and bread quality parameters such as specific volume, textural characteristics, image processing, differential scanning calorimetry (DSC), scanning electron microscope (SEM) were determined by Response Surface Methodology (RSM) using a central composite design.

Results: The results showed that the addition of quinoa flour decreased specific volume, porosity and increased firmness, but addition of xanthan increased springiness. According to the results, optimized sample was selected of the $9.1 \%$ quinoa flour and $1.25 \%$ xanthan gum. Then, structure of starch granules, enthalpy, crude fiber and mineral content of optimized and control samples were evaluated. Results showed that crude fiber and mineral content of optimized sample were increased as compared to control bread. In spite of that, the enthalpy of fortified sample was higher.

Conclusions: Due to appropriate nutritional value of quinoa flour and proper effect of xanthan on texture, therefore this ingredient could be used as substitute for wheat flour in Barbari formulation.

Keywords: Fiber, Barbari, Functional food

\section{Introduction}

Bread is the main bakery product consumed in Iran. Generally, five types of bread are bake in Iran; Sangak, Taftoon, Barbari and Lavash breads are among the most widely baked breads. Barbari, which is known as an oven-baked bread, is generally consumed in North and North-west of Iran. This bread is usually 70 to $80 \mathrm{~cm}$ long and 25 to $30 \mathrm{~cm}$ wide, with thickness of about $20 \mathrm{~cm}$ (1). One of the suitable approaches for fortifying and improving the functional properties of breads is substitution with fiber-rich sources such as Aleo vera powder (2), barley, rye, oat grains (3), quinoa leaf (4), hydrocolloids (5) and barley bran (6).

Pseudo-cereals belong to Dicotyledonous plants (7), cultivated in different countries in Africa, Asia,
Central and South America, and are being rediscovered in the last thirty years. Among the Chenopodium family, amaranth, quinoa and buckwheat are more important and are known as pseudocereals around the world. Pseudo-cereals could be used in bread formulation in order to increase its nutritional value (8). The nutritional value of pseudocereals is mainly related to their constituting proteins (9). They have a medium quantity of calcium and therefore are suitable for vegetarians and lactose intolerance patients. In addition, due to the lack of prolamine, they are appropriate for gluten free products for celiac patient (10).

Quinoa (Chenopodium quinoa willd.) is a native plant of Andean region, and known not only for its 
high protein level, but also for proper amino acid balance (11). This plant is also a good source of dietary fiber and vitamins such as thiamin, riboflavin, folate as well as great source of minerals like ferric, magnesium, phosphorus, copper, zinc and manganese (12). Quinoa has a considerable amount of phenolic components like flavonoids and overall antioxidants, in addition to containing essential fatty acids like oleic and linoleic acids (13). Because of its appropriate nutritional value, Quinoa is currently considered by FAO as the food of the future due to its contribution to global food safety of the 21st century. The year 2013 was thus denominated the International Year of Quinoa (14).

One of the major problems of bakery products is staling and alteration of rheological properties during storage period. Staling is a complicated process that involves physical, chemical and organoleptic changes during storage which reduces the consumer acceptance. This process is along with transformation of texture, moisture migration, and starch crystallization, alteration of gluten network or interaction with starch granules, reduction of water holding capacity, compressibility and $\alpha$-amylase sensibility (15). Hydrocolloids or gums are large groups of polysaccharides and their derivations are wildly utilized in food industries to enhance textural and rheological characteristics. Hydrocolloids have the potential to absorb water which postpone the migration of moisture into the surface of bread and therefore decelerate the staling process. Many researchers have investigated the effect of quinoa flour on the bread (16), gluten-free (17) and cereal based food products (18). However, the role of quinoa flour on the quality characteristics of flat breads has not been investigated so far. Thus, the objective of this study is to produce and optimize the formulation of enriched and functional Barbari bread.

\section{Materials and Methods}

Material: Flour with a extraction percent of $82 \%$ from (Jonob Flour Co, Iran), Active Dry yeast (Razavi yeast Co, Iran), Salt (Spidan Co, Iran), Bread Improvers (Omaj Co., Iran), Xanthan Gum (Sigma Co., Germany) and Quinoa flour with a extraction percent of $96 \%$ (Seed and Plant Improvement Institute, Iran) were provide.

Bread preparation: In this study, Barbari bread was produced based on a method described by the
Standard no. 5809 (Industrial research center of Iran). For preparation of bread, $125 \mathrm{gr}$ of wheat flour with the extraction rate of $82 \%$, was mixed with salt $(2 \%)$, active dried yeast (1\%), improving agent $(0.3 \%)$, quinoa flour $(0-15 \%)$, xanthan gum $(0-1.5 \%)(\mathrm{w} / \mathrm{w}$ flour basis), and sufficient amount of water (40-60\%) to produce dough with appropriate consistency (Determined by farinograph). Then, the dough rested for $30 \mathrm{~min}$ for the first fermentation stage and after that was divided in pieces which weighed about 200 g. Dough pieces were fermented again for $15 \mathrm{~min}$, followed by rounding and incubating for $45 \mathrm{~min}$ at $35^{\circ} \mathrm{C}$ and $7 \%$ humidity for final proofing. Finally, baking was done in oven (Karl Welker KG., Wiesloch, Germany) at temperature of $240^{\circ} \mathrm{C}$ for 15 min. After cooling, bread samples were packed in polyethylene bags and stored at room temperature.

Specific volume: The volume of the breads was determined using the rapeseed displacement according to AACC method 10-05 (19) with seed displacement technique. The weight of samples was measured using an analytical balance (model GF-200, Japan). The specific volume (SV) of the treatments was calculated by dividing the volume by the weight. Each measurement was performed in triplicate.

Textural characteristics: Firmness and springiness was evaluated according to AACC method 74-09 (19) and the method described by Purhagen et al. (2011) (20), respectively. Texture of the samples was investigated 2 hours after baking using a TA.XT2i Texture Analyzer (Stable Micro Systems, Goldalming, UK) equipped with a $5 \mathrm{~kg}$ load cell and a $\mathrm{P} / 35 \mathrm{~mm}$ aluminum cylindrical probe with $1.7 \mathrm{~mm} / \mathrm{s}$ speed, $40 \%$ of deformation and holding for $32 \mathrm{~s}$. Values of firmness (Newton) and springiness (\%) were calculated using the Texture Exponent software (version 5.1.1.0, Stable Microsystems, Godalming, UK).

Image processing: The bread crumb properties were evaluated using image analysis system which consists of a digital camera (canon) and PC. Images captured in format 24-bits, from $30 \mathrm{~cm}$ above samples in a black box $(100 \times 100 \times 100 \mathrm{~cm})$ and lighting by fluorescent lamp from $45^{\circ}$ angle. Images were transferred to ImageJ software (NIH, Bethesda, Maryland) and the structural features of bread crumb were evaluated. In order to create binary images, this procedure was utilized. After contrast enhancement of image, the image segmented using the Otsu 
algorithm, which produces highly uniform binary images. Finally, images with dark and white spots were generated. Then bread crumb properties were studied by determination of total number, density, area of cells, and porosity (area of the cells/total area ratio) (21).

Differential Scanning Calorimetry (DSC): Differential scanning calorimetry (Setaram instrumentation, France) was used to evaluate the enthalpy changes $(\Delta H)$ in the crumb over storage time $(1,3$, and 5 days). For this purpose, 15-20 mg of dried crumb of control and optimized samples were put and sealed in the pan and were scanned from $25-150{ }^{\circ} \mathrm{C}$ at 10 ${ }^{\circ} \mathrm{C} / \mathrm{min}$. The endothermic peak area was converted to enthalpy that was used as an index of starch recrystallization. An empty aluminum pan was used as a reference whereas the instrument was calibrated with Indium. Then, in order to evaluate amylopectin retrogradation, DSC curve was drawn. The parameters recorded were onset temperature $\left(T_{0}\right)$, peak temperature $\left(\mathrm{T}_{\mathrm{p}}\right)$ and final temperature $\left(\mathrm{T}_{\mathrm{c}}\right)$ of gelatinization and retrogradation transitions (22).

Scanning electron microscope (SEM): For SEM analysis, control and optimized bread crumb which were cut in cubes were frozen in liquid nitrogen and freeze dried. After that, samples were coated with gold-palladium and scanned with scanning electron microscope (Philips XL30, Nederland). The magnitude was $\times 10, \times 500$ and $\times 1000$. The crust and crumb of breads were scanned with magnitude of $\times 10$ and $\times 500$, and the molecular structure of starch and gluten network were examined with magnitude of $\times 1000(23)$.

Minerals: Evaluation of mineral composition within bread samples was conducted by Atomic absorption and Flame photometer (Analytik jena, contra AA 300, Germany) according to AACC method40-70 (19).

Crude fiber: Crude fiber was measured according to AOAC method 991.4(24).

Experimental design and data analysis: Central composite rotatable design (CCRD) with two factors in three levels was applied to evaluate production parameters and optimization. Five replications for central point were considered. Minitab software (version 16) was used for experimental design, data analysis and optimization. Complete second order equation was fitted through backward multiple stepwise regression. Independent variables are quinoa $\left(\mathrm{X}_{1}\right)$ in the range of $0-15 \%$ and xanthan $\left(\mathrm{X}_{2}\right)$ in the range of $0-1.5 \%$.

A quadratic model was selected, where 13 combinations were generated via the Minitab software. A second-order polynomial equation was fitted to the obtained experimental data for responses:

In this equation: $Y$ is estimated respond and $\beta_{0}$ is the defined as the constant, $\beta_{\mathrm{i}}$ is the linear coefficien, $\beta_{\mathrm{ii}}$ is the quadratic coefficien and $\beta_{\mathrm{ij}}$ is the interaction coefficien. Also $x_{i}$ and $x_{j}$ are the levels of independent variables. Analysis of variance was significant for each respond. Also, Lack-of-fit, coefficient of determination $\left(R^{2}\right)$, adjusted $R^{2}$ (adj-R2) coefficient of variation $(\mathrm{CV})$ and PRESS were calculated to check the model adequacy (21).

In the optimization stage, critical characteristics can be defined as max, min and middle levels. Fitted models can be used for optimization purposes through desirability functions. So, in order to achieve optimum level of dependent variables such as specific volume, springiness, firmness and image processing attributes, Minitab optimization tool were employed and then the formal maximum desirability was selected as optimum treatment. In order to validate method, bread was baked according to optimum conditions and experimental results were compared to predicted variables. Then, the characteristics of optimized sample such as crude fiber, minerals, SEM and DSC were evaluated.

\section{Results}

Analysis of variance demonstrated that a significant second-order polynomial model was found for the effects of independent variables on all responses $(p<0.01)$. The quality of fitness of models was assessed by a lack-of-fit test $(p>0.05$ for all responses) which determines model accuracy to predict variation (Table 1).

Specific volume (SV): Results showed that SV decreased by the addition of quinoa flour in samples. These results were in agreement with Iglesias et al. (2015) (16). Findings showed that SV decreased by increasing the ratio of quinoa flour in bread dough formulation. Fig.1. (a) showed the response surface plot of formula variables on SV parameter of breads. 
Shima Jaldani, et al: Optimization of Pproperties of Bread Enriched With Quinoa Flour

Table 1. Regression coefficients of the second-order polynomial equations for imaging responses

\begin{tabular}{|c|c|c|c|c|c|c|c|}
\hline Source & $\begin{array}{l}\text { Cell density } \\
\left(\mathrm{g} / \mathrm{cm}^{3}\right)\end{array}$ & $\begin{array}{c}\text { Average cells area } \\
\qquad\left(\mathrm{m}^{2}\right)\end{array}$ & Count & $\begin{array}{l}\text { Firmness } \\
(\mathrm{N})\end{array}$ & $\begin{array}{l}\text { Springiness } \\
(\mathrm{m} . \mathrm{m})\end{array}$ & $\begin{array}{l}\text { Specific volume } \\
\left(\mathrm{m}^{3} / \mathrm{Kg}\right)\end{array}$ & $\begin{array}{c}\text { Porosity } \\
\text { (\%) }\end{array}$ \\
\hline$\beta_{0}$ & 0.01 & 26.14 & 124.43 & 4.89 & 59.74 & 4.93 & 17.64 \\
\hline$\beta_{1}$ & $0.0002^{* * * *}$ & $0.63^{\mathrm{ns}}$ & $72.32^{*}$ & $-0.11^{*}$ & $0.98^{* *}$ & $0.05^{* * * * *}$ & $-0.57^{\mathrm{ns}}$ \\
\hline$\beta_{2}$ & $-0.006^{\mathrm{ns}}$ & $35.22^{* * * * *}$ & $1332.82^{\mathrm{ns}}$ & $-0.90^{* *}$ & $-0.75^{* * * * *}$ & $1.48^{\mathrm{ns}}$ & $3388^{* * * * *}$ \\
\hline$\beta_{1} \beta_{1}$ & $3.08^{\mathrm{ns}}$ & $-0.01^{\mathrm{ns}}$ & $-5.93^{* * *}$ & $0.02^{* * *}$ & $-0.06^{* * * * *}$ & $-0.01^{\text {** }}$ & $0.03^{\mathrm{ns}}$ \\
\hline$\beta_{2} \beta_{2}$ & $0.005^{*}$ & $-8.35^{\mathrm{ns}}$ & $-865.33^{* * * *}$ & $2.33^{* * * *}$ & $4.94^{* * *}$ & $-1.03^{* *}$ & $-12.40^{* * *}$ \\
\hline$\beta_{1} \beta_{2}$ & $1.46^{\mathrm{ns}}$ & $-0.18^{\mathrm{ns}}$ & $-0.35^{\mathrm{ns}}$ & $-0.25^{\text {**** }}$ & $-0.35^{*}$ & $0.04^{\mathrm{ns}}$ & $-0.23^{\mathrm{ns}}$ \\
\hline Model (p-value) & $0.002^{* *}$ & $0.002^{* *}$ & $0.001^{* * *}$ & $0.001^{* * * *}$ & $0.005^{* *}$ & $0.001^{* * * *}$ & $0.0000^{* * * * *}$ \\
\hline Lack of fit (p-alue) & $0.065^{\mathrm{ns}}$ & $0.28^{\mathrm{ns}}$ & $0.054^{\mathrm{ns}}$ & $0.54^{\mathrm{ns}}$ & $0.67^{\mathrm{ns}}$ & $0.837^{\mathrm{ns}}$ & $0.053^{\mathrm{ns}}$ \\
\hline $\mathrm{R}^{2}$ & 90.83 & 90.21 & 92.28 & 93.46 & 95.90 & 91.67 & 95.32 \\
\hline Adj- $R^{2}$ & 84.28 & 83.22 & 86.77 & 88.89 & 92.97 & 85.72 & 91.98 \\
\hline $\mathrm{CV}(\%)$ & 19.90 & 19.12 & 39.60 & 9.25 & 3.96 & 8.66 & 22.17 \\
\hline PRESS & 0.0008 & 516.821 & 312174 & 2.44 & 11.86 & 0.73 & 161.20 \\
\hline
\end{tabular}

ns: No significant $*$ Significant at $\mathrm{p} \leq 0.05$. ** Significant at $\mathrm{p} \leq 0.01$. *** Significant at $\mathrm{p} \leq 0.001$. **** Significant at $\mathrm{p} \leq 0.0001$

$\beta_{0}$ : constant, $\beta_{2}$ : linear coefficient of Quinoa, $\beta_{2}$ : linear coefficient of Xanthan,

Firmness: Fig. 1. (b) demonstrated the effect of formula variables on firmness. Results of wheat flour substitution by quinoa flour and xanthan gum showed that firmness increased with higher quinoa flour content: hardest samples consisted of $12.8 \%$ quinoa flour and $0.21 \%$ xanthan gum and the softest had $7.6 \%$ quinoa and $0.75 \%$ xanthan gum. Response surface plot also shows similar results.

Springiness: Treatment of $7.5 \%$ quinoa and $1.5 \%$ xanthan gum showed the highest springiness. Results revealed that xanthan gum had the most influence on springiness which could be related to water holding capacity of hydrocolloids.

Image processing: Findings in Fig. 1. (c) showed that count of cells was positive and significant $(p<0.05)$ for linear effect of quinoa flour, but not significant and positive for linear effect of xanthan gum. The quadratic effect of xanthan gum and quinoa flour $(p<0.001)$ were significant. Assessment of crumb properties in Fig.1. (d) show that the average of cell area was positive and not significant for linear effect of quinoa flour, but significant and positive for linear effect of xanthan gum $(\mathrm{p}<0.0001)$. Other coefficients were negative and not significant (Table 1). The results of cell density in Fig.1. (e) also show that the linear effect of quinoa flour $(\mathrm{p}<0.0001)$ and quadratic effect of xanthan gum $(\mathrm{p}<0.05)$ were significant, but other coefficients were not considerable (Table 1). On the other hand, Fig.1. (F) show that the most porosity was in treatment with $0 \%$ quinoa and $0.75 \%$ xanthan gum which has the most similarity to the control sample. The lowest porosity was observed in sample of $7.5 \%$ quinoa and $0 \%$ xanthan gum. Table 1 shows that the influence of xanthan gum, as the addition on porosity was more than quinoa flour. Thus the linear effect of quinoa flour on porosity was negative and not significant but quadratic effect of xanthan gum was negative but significant $(\mathrm{p}<0.01)$. Increasing of substitution level enlarged the pore size and their average area, but decreased porosity. These could be related to the reductions in gluten amount by the substitution, which led to the formation of weak gluten network during fermentation. Addition of quinoa also induced a rough texture in bread which prevents from fine pore formation. Therefore, bread samples have larger pore but did not change porosity.

Optimization: The numerical optimization was performed to calculate optimal values for independent variables. The most desired formulation with high desirability $(\mathrm{D}=0.64)$ was chosen to produce a high quality product. Based on optimization results, the selected sample consisted of $9.10 \%$ quinoa flour and $1.25 \%$ xanthan gum. 


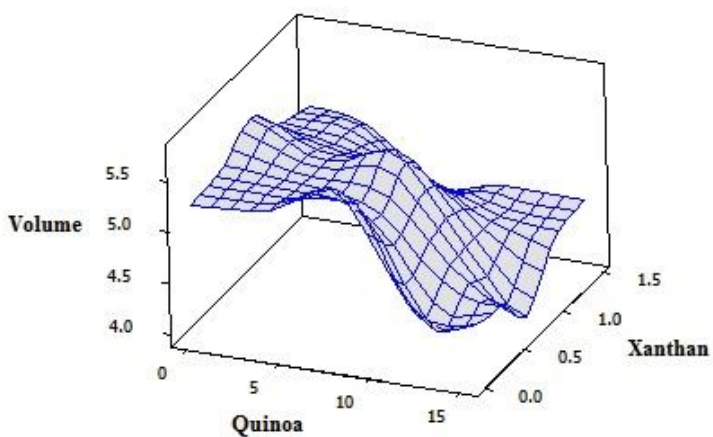

(a)

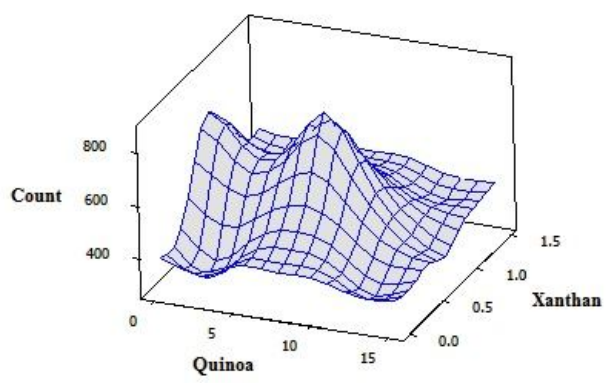

(c)

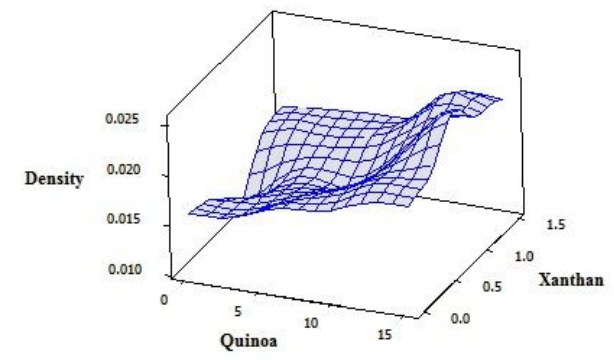

(e)

Fig 1. Response surfaces plots for the effects of: (a): Specific volume ( $\left.\mathrm{m}^{3} / \mathrm{Kg}\right)$, (b): Firmness (N), (c): Count (d): Average Size $\left(\mathrm{m}^{2}\right)(\mathrm{e})$ : Density $\left(\mathrm{g} / \mathrm{cm}^{3}\right),(\mathrm{f})$ : Porosity $(\%)$.

Scanning Electron Microscope (SEM): Fig. 2. (a) and (b) represent microscopic structure of optimized and control samples in the first day of baking, respectively. As shown in figures, structure of optimized bread with quinoa flour and xanthan gum had no significant differences with the control sample in porosity and pore size. Due to the addition of quinoa flour and its influence on gluten network, it is expected that there was a difference between structures of optimized and control samples, but this

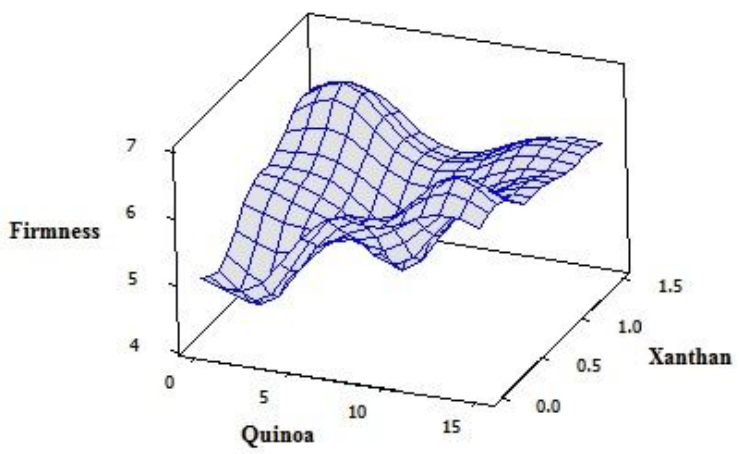

(b)

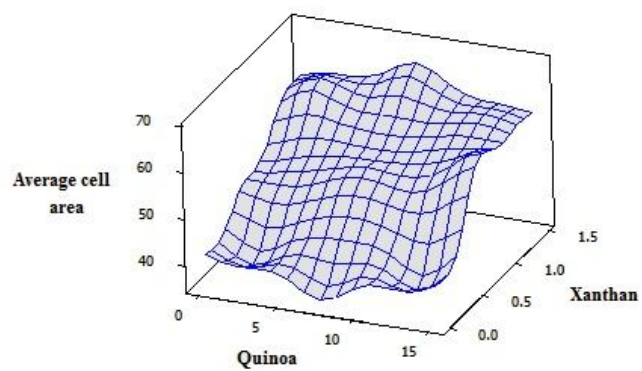

(d)

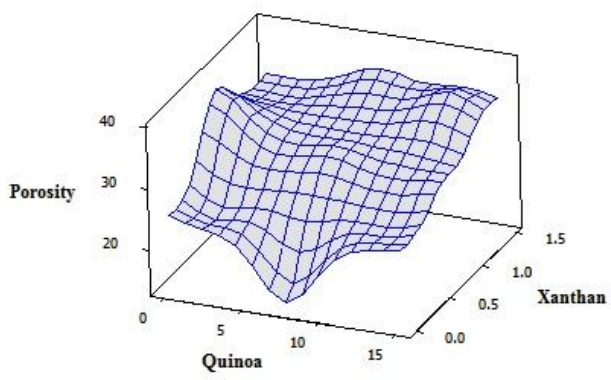

(f) 


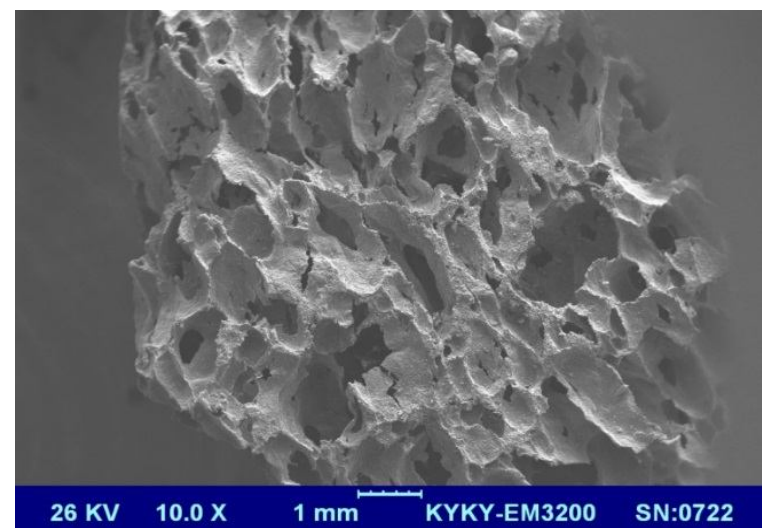

(a)

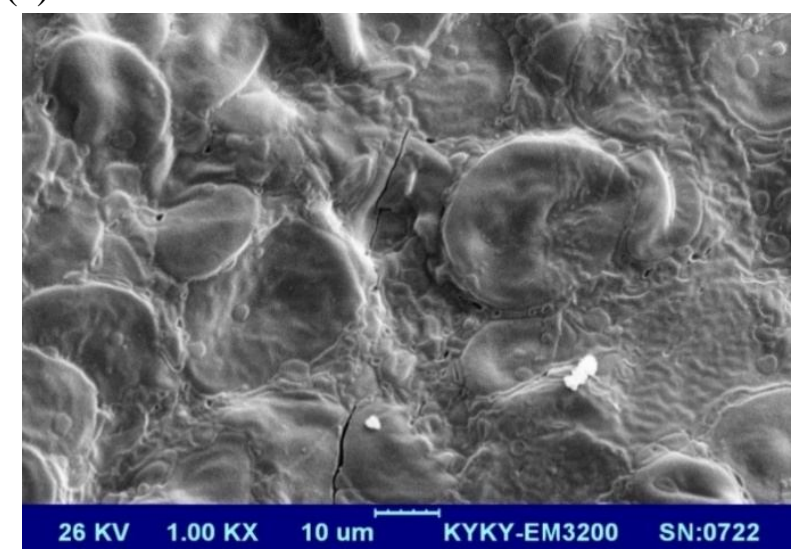

(c) (b)

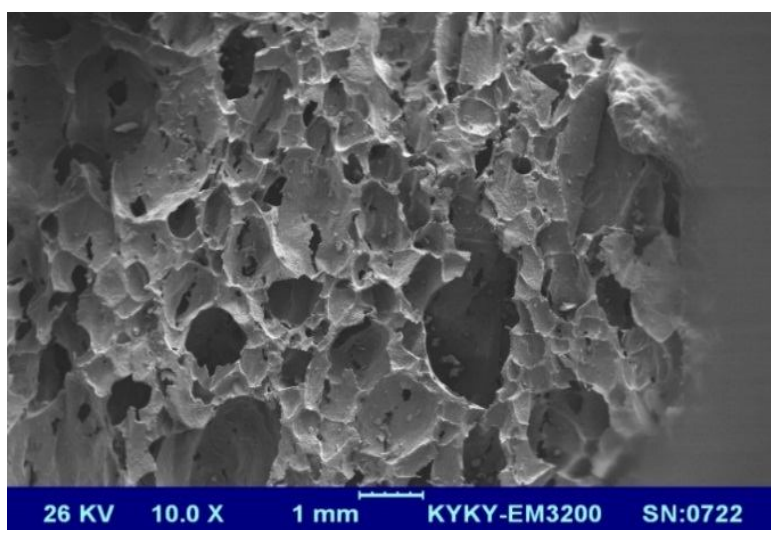

(d)

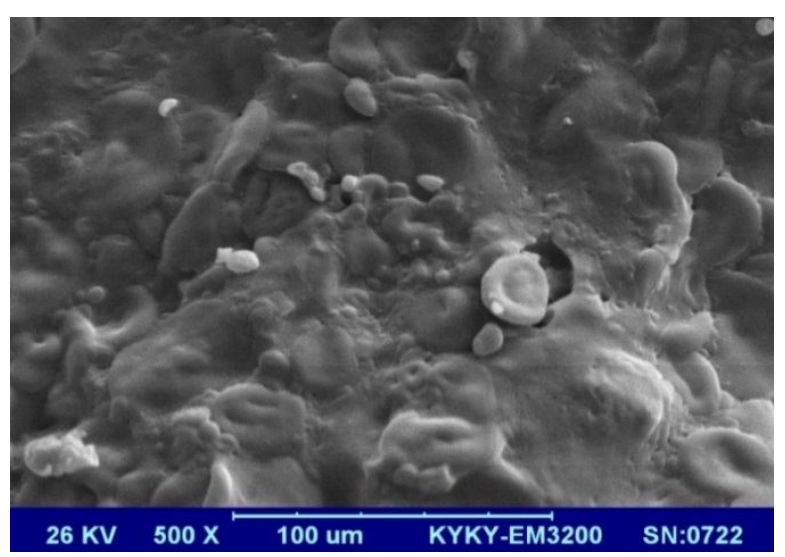

Fig 2. SEM image of Barbari bread with quinoa flour and XG: (a) control sample, (b) optimized sample. And starch granule: (c) optimized sample, (d) control sample

Table 2. Minerals content in flour and breads(mg/l)

\begin{tabular}{ccccc}
\hline mineral & Control Bread & Optimized bread & Wheat Flour & Whole Quinoa Flour \\
\hline $\mathrm{Cu}$ & $1.12 \pm 0.03^{\mathrm{D}}$ & $12.09 \pm 0.01^{\mathrm{B}}$ & $2.24 \pm 0.06^{\mathrm{C}}$ & $12.61 \pm 0.05^{\mathrm{A}}$ \\
$\mathrm{Fe}$ & $2.10 \pm 0.03^{\mathrm{D}}$ & $8.26 \pm 0.07^{\mathrm{A}}$ & $4.24 \pm 0.03^{\mathrm{C}}$ & $4.62 \pm 0.03^{\mathrm{B}}$ \\
$\mathrm{Zn}$ & $4.28 \pm 0.06^{\mathrm{C}}$ & $22.11 \pm 0.03^{\mathrm{A}}$ & $2.42 \pm 0.02^{\mathrm{D}}$ & $9.50 \pm 0.04^{\mathrm{B}}$ \\
$\mathrm{Mn}$ & $3.84 \pm 0.05^{\mathrm{C}}$ & $8.74 \pm 0.04^{\mathrm{A}}$ & $3.36 \pm 0.3^{\mathrm{D}}$ & $7.80 \pm 0.05^{\mathrm{B}}$ \\
$\mathrm{Ca}$ & $14.25 \pm 0.2^{\mathrm{D}}$ & $22.18 \pm 0.03^{\mathrm{C}}$ & $34.36 \pm 0.04^{\mathrm{B}}$ & $44.22 \pm 0.05^{\mathrm{A}}$ \\
$\mathrm{K}$ & $2.53 \pm 0.02^{\mathrm{B}}$ & $3.15 \pm 0.04^{\mathrm{A}}$ & $2.43 \pm 0.03^{\mathrm{D}}$ & $9.72 \pm 0.04^{\mathrm{C}}$ \\
$\mathrm{Na}$ & $5.35 \pm 0.05^{\mathrm{B}}$ & $8.47 \pm 0.04^{\mathrm{C}}$ & $1.74 \pm 0.03^{\mathrm{D}}$ & $2.45 \pm 0.03^{\mathrm{A}}$ \\
\hline Numbers followed by the same letter are not significantly differentns in the r $(\mathrm{P}<0.05)$
\end{tabular}

Crude fiber: Measurement of crude fiber content in Fig 3 shows that in comparison to the flour and bread of wheat, flour and bread of quinoa had higher fiber content. Also baking process had no significant effect on this portion of final product.

\section{Differential Scanning Calorimetry (DSC):}

Crystalline and semi crystalline structure of native starch was converted to amorphous due to gelatinization during baking. After that, some degree of crystallization occurs in the storage period. If staled bread was exposed to further heating, the required energy for melting of crystals can be measured, which is defined as staling index. As a result, enthalpy increased during the shelf life and progress of retrogradation stage (22). The results of DSC analysis for Barbari breads are shown in Fig 4. The analysis of enthalpy $(\Delta \mathrm{H})$ results for fresh samples showed significant differences: the enthalpy of control bread was higher than optimized bread. But during storage and in third day, significant differences and enthalpy of optimized sample was lower than control bread. 


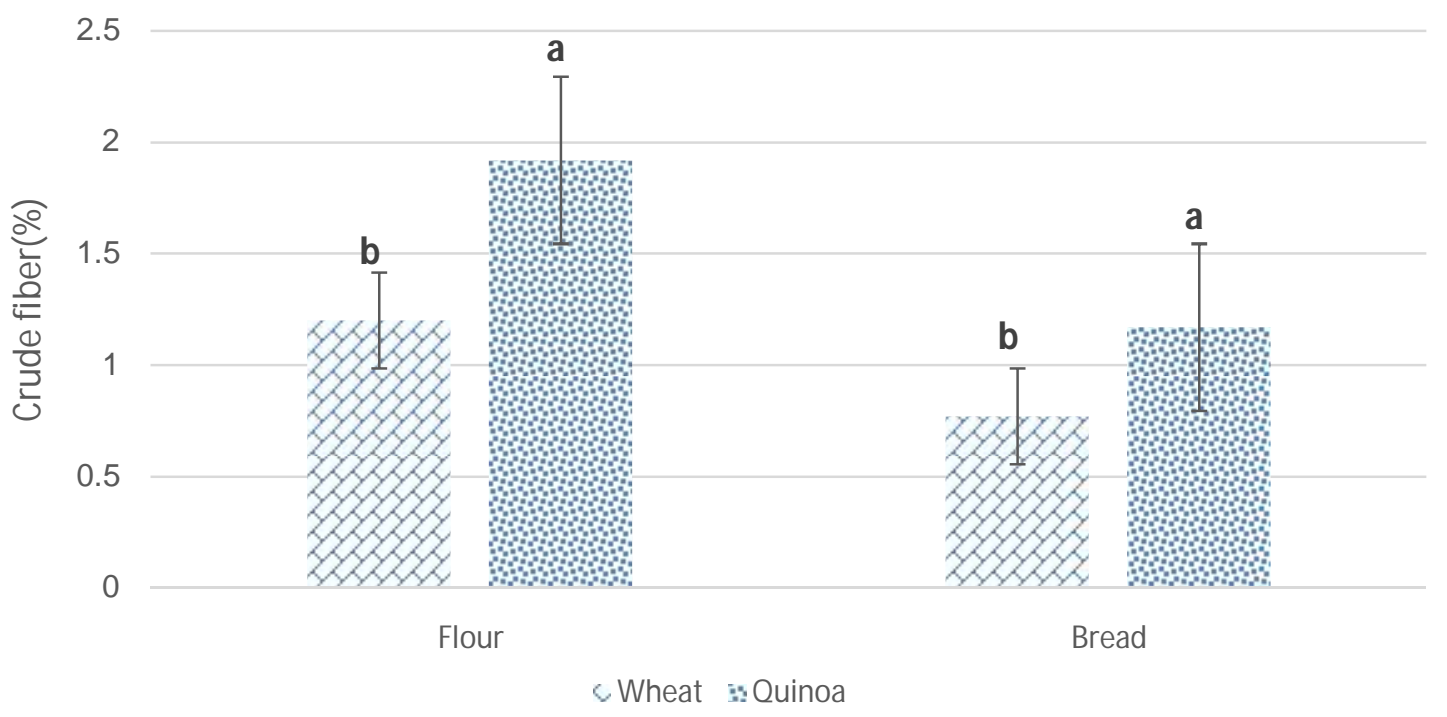

Fig 3. Crude fiber of flours and breads

Numbers followed by the same letter are not significantly differentns in the samples $(\mathrm{P}<0.05)$

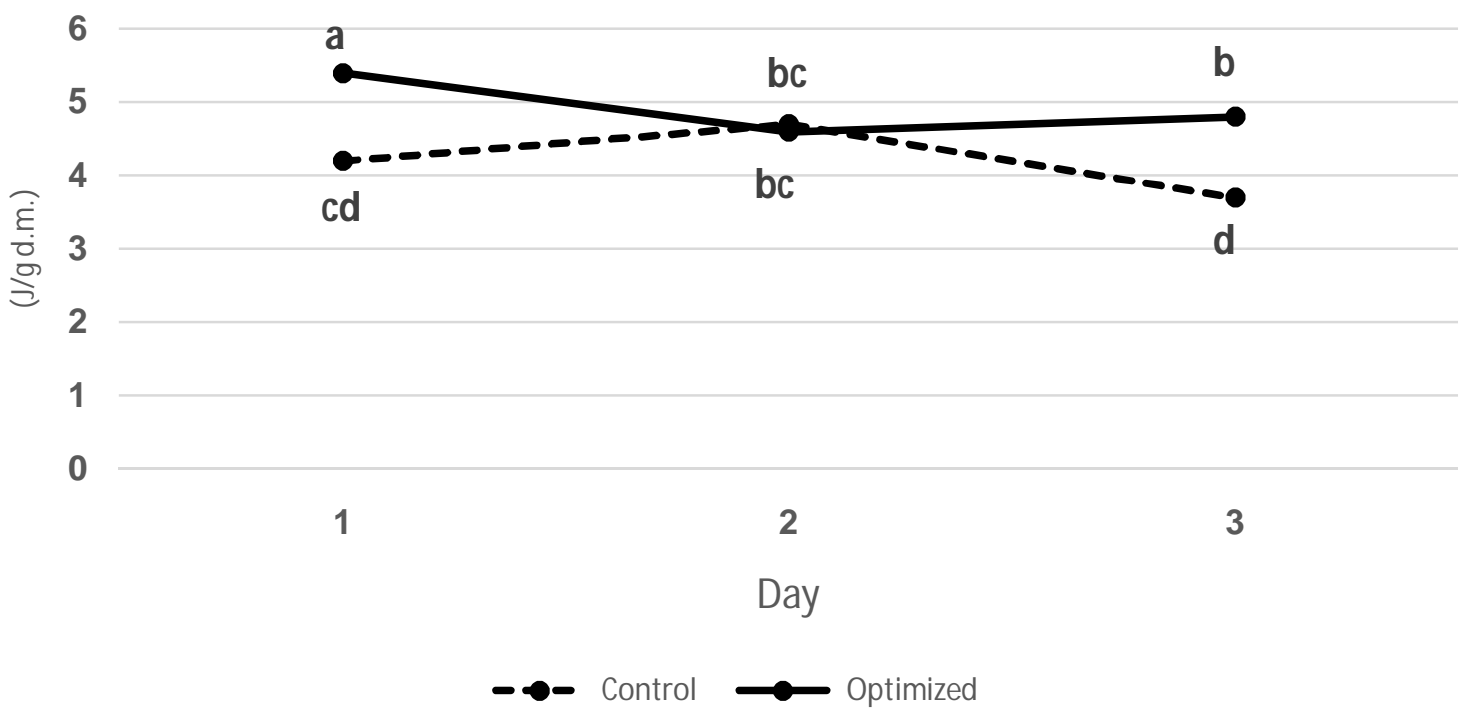

Fig 4. Enthalpy of breads during storage

Numbers followed by the same letter are not significantly differentns in the samples $(\mathrm{P}<0.05)$

\section{Disc ussion}

Specific volume (SV): The reduction could be related to decreasing strength of dough in gas holding capacity due to the lack of gluten in quinoa flour and high amount of albumin and globulin. Sciarini et al. (2010) observed that lower ratios of soybean flour in bread formulation, enhanced physical properties of bread and increased SV, which led to the soften texture and weakened staling. However, due to the increasing of fat in higher amount of soybean flour, SV decreases and gas holding capacity reduced (25). Study of volume and texture properties of gluten free bread from quinoa white flour showed that SV increased due to the absence of bran and high glucosides activity in white flour (26).

Firmness: Increasing firmness in bakery products due to the addition of edible fibers has been reported in various studies $(27,2)$. Addition of whole quinoa 
flour (up to 50\%) had significant effect on bread properties such as increasing firmness, darkness and SV (Iglesias et al., 2015). Also, investigation of technological and physicochemical properties of fortified bread with other fiber-rich cereals showed that addition of such components increased firmness and accelerated retrogradation of amylopectin, due to weakening of gluten network and reduction of gas holding capacity (28).

Springiness: Kadan et al. (2001) evaluated the textural and physicochemical properties of whole rice flour bread and reported the reduction in springiness, cohesiveness and chewiness compared to wheat bread (29). Therefore, rice bread is more brittle than wheat bread. Investigation of rheological properties and bread quality of frozen sweet dough showed that the addition of xanthan gum increased springiness in comparison to control sample (30). In another research, it has been observed that $25 \%$ and $50 \%$ of substitution in wheat flour with whole quinoa flour had no significant difference in springiness compared to control sample. (16). Assessment of xanthan gum addition effect on steamed bread showed that $1 \%$ of xanthan gum enhanced springiness and other textural characteristics of this product (31).

Image processing: Das et al. (2015) evaluated the effects of some hydrocolloids such as xanthan gum, guar gum and carboxymethyl cellulose (CMC), on texture of bread enriched with coriander. Results showed that this ingredient decreased cell area but in return increased the pore count and porosity compared to control sample (32). Addition of chia flour also increased cell density and cell average size (33). Evaluation of malt and quinoa flour addition on bread, demonstrated that malt flour decreased cell density but increased cell count due to the increasing of $\alpha$-amylase activity, which is effective in gas cell strength (17).

Scanning Electron Microscope (SEM): The amount of protein and presence of hydrocolloid have major roles in porosity and staling (23). Hydrocolloids formed a thick layer around gas cells and subsequently stabilized them. The presence of this layer led to attachment of cells and increasing porosity (5). Fig. 2. (c) and (d) is the illustration of the granule structure of starch in control and optimized samples. This structure in optimized sample was more shrunken and brighter, which represents more rapid retrogradation of starch granules. Therefore, due to smaller starch granule and higher amount of amylopectin in quinoa flour, the staling process occurred rapidly (18). Analyzing the SEM images of gluten free bread fortified with wheat, corn, oat and barley bran, showed that bran addition enhanced the structure of starch matrix which led to fewer and larger pores. In addition, images also showed a continuous network between starch granules and fiber of barley and corn which made the bread structure more porous (27).

Mineral content: This could be due to the addition of whole quinoa flour, as Stikic et al. (2012) showed that white quinoa flour (without bran) decreased mineral content of final product (34). Jancurová et al. (2009) have been proved that dehulling of quinoa reduced ferric, zinc and potassium up to $12-15 \%$, and copper and magnesium to the $27 \%$ and $3 \%$, respectively (35). Crude fiber: Iglesias et al. (2015) reported that addition of quinoa whole flour to bread formulation increased crude fiber of final products. Moreover, comparison of four varieties of quinoa, wheat, barley and corn showed that all varieties of quinoa had the highest crude fiber content among other cereals (16). So quinoa could be considered as a good source of fiber (13).

Differential Scanning Calorimetry (DSC): This could be related to the higher fat content of optimized samples (36). Furthermore, soluble and insoluble fiber with high water holding capacity could increase dough stability and postpone staling. On the other hand, weakening of gluten network makes recrystallization of amylopectin more difficult, which is coordination with Iglesias et al. (2015) (16). However, in the fifth day of storage, enthalpy of quinoa sample increased compared to the third day, but decreased in control sample. It seems that oxidation of lipids in optimized bread increased enthalpy and accelerated staling. Although according to the Nasehi et al. (2005), DSC results of flat breads is reliable for up to three days after baking (22).

\section{Conclusion}

In this study, a bread formula with high fiber content was developed by incorporation of xanthan gum and whole quinoa flour. Response surface methodology was an appropriate technique for modeling and optimization of the effects of xanthan gum and whole quinoa flour on physical and visual characteristics of the bread. Enrichment of wheat bread with quinoa flour decreased SV, porosity and 
increased firmness. According to the results, samples of $9.1 \%$ quinoa flour and $1.25 \%$ xanthan gum was selected as optimized sample. Findings also showed that crude fiber and mineral content of optimized bread were increased in comparison to control sample. On the other hand, SEM and DSC observation showed that the amount and rate of starch retrogradation in breads with whole quinoa flour were higher than control breads, which is due to the high amount of amylopectin in the quinoa flour. Additionally, the addition of whole quinoa flour to the Barbari bread formulation improved nutritional properties such as crude fiber and minerals. Quinoa is a high potential grain to help global food security. This grain is rich in amino acids and some important minerals. However, appropriate nutritional and digestibility properties of quinoa flour, makes it a suitable option for enrichment of bread formulation and can be used in production of functional breads.

\section{Financial disclosure}

The authors declared no financial interest.

\section{Funding/Support}

This research project was financially supported by Khuzestan Agricultural Sciences and Natural Resources University of Iran.

\section{References}

1. Ghanbari M, Farmani J. Influence of hydrocolloids on dough properties and quality of barbari: an Iranian leavened flat bread. J Agric Sci Tech. 2013;15(3):54555.

2. Nasehi B, Razavi SMA, Ghodsi M. Investigation of the effect of aloe vera powder on the properties of Barbari bread during storage. J Food Sci and Techol. 2016; 51(13): 195-203.

3. Ragaee S, Guzar I, Dhull N, Seetharaman K. Effects of fiber addition on antioxidant capacity and nutritional quality of wheat bread. LWT Food Sci. Technol. 2011; 44(10); 2147-2153.

4. Świeca M, Sęczyk Ł, Gawlik-Dziki U, Dziki D. Bread enriched with quinoa leaves-The influence of proteinphenolics interactions on the nutritional and antioxidant quality. Food chem. 2014;162: 54-62.

5. Bagheri H, Koocheki A, Mohebbi M. Effects of Leidium perfoliatum seed and xanthan gums on physical properties of pan bread. J Food Sci Tech. 2016; 58(13): 117-129.

6. Andersson AA, Lampi AM, Nystro $\square \mathrm{m}$ L, Piironen V, Li L, Ward JL, Gebruers K, Courtin CM, Delcour JA, Boros D, Fras A. Phytochemical and dietary fiber components in barley varieties in the HEALTHGRAIN diversity screen. J Agric Food Chem. 2008;56(21):9767-76.

7. Fletcher RJ. Pseudo cereals Overview. In: Wrigley, C.: Encyclopedia of grain science. Vol. 2. Oxford: Elsevier Academic Press. 2004; 488-494.

8. Aghamirzaei M, Heydari-Dalfard A, Karami F, Fathi M. Pseudo-cereals as a functional ingredient: effects on bread nutritional and physiological Properties-Review. Int J Agric Crop Sci. 2013; 5(14), 1574.

9. Mota C, Santos M, Mauro R, Samman N, Matos AS, Torres D, Castanheira I. Protein content and amino acids profile of pseudocereals. Food chem. 2016;193: 55-61.

10. Schoenlechner R, Drausinger J, OttenschlaegerV, Jurackova K, Berghofer E. Functional properties of gluten-free pasta produced from amaranth, quinoa and buckwheat. Plant Plant Foods Hum Nutr. 2010; 65(4): 339-349.

11. Escuredo O, Martín MIG, Moncada GW, Fischer S, Hierro JMH. Amino acid profile of the quinoa (Chenopodium quinoa Willd.) using near infrared spectroscopy and chemometric techniques. J Cereal Sci.2014; 60(1), 67-74.

12. Nowak V, Du J, Charrondière UR. Assessment of the nutritional composition of quinoa (Chenopodium quinoa Willd.). Food chem. 2016; 193, 47-54.

13. Repo-Carrasco-Valencia R, Hellstrom JK, Pihlava JM, Mattila PH. Flavonoids and other phenolic compounds in Andean indigenous grains: Quinoa (Chenopodium quinoa), kañiwa (Chenopodium pallidicaule) and kiwicha (Amaranthus caudatus). Food Chem. 2010; 20(1), 128-133.

14. FAO. Food and Agriculture Organization of the United Nations. International Year of the Quinoa IYQ-2013. Retrieved August 07, from http://www.rlc.fao.org/ en/about-fao/iyq-2012/.

15. Nasehi B, Azizi MH, Hadian Z. Different approaches for determination of bread staling. J Food Sci Techol. 2009; 6(1):53-63.

16. Iglesias-Puig E, Monedero V, Haros M. Bread with whole quinoa flour and bifidobacterial phytases increases dietary mineral intake and bioavailability. LWT-Food Sci Technol. 2015;60(1), 71-77.

17. Mäkinen OE, Zannini E, Arendt EK. Germination of oat and quinoa and evaluation of the malts as gluten free baking ingredients. Plant Foods Hum Nutr. 2013;68(1): 90-95.

18. Valcárcel-Yamani B, Silva Lannes SC. Applications of quinoa (Chenopodium quinoa Willd.) and amaranth (Amaranthus Spp.) and their influence in the nutritional value of cereal based foods. Food and Public Health. 2012;2(6): 265-275.

19. AACC. Approved method of the American association of cereal chemists, 9th end. 1999; American association of cereal chemists, Inc., Minnesota. 
20. Purhagen JK, Sjöö ME, Eliasson AC. Starch affecting anti-staling agents and their function in freestanding and pan-baked bread. Food Hydrocolloids. 2011;25(7): 1656-1666.

21. Nouri M, Nasehi B, Samavati V, Abdanan SM. Optimizing the effects of Persian gum and carrot pomace powder for development of low-fat donut with high fibre content. Bioact Carbohydr Dietary Fibre. 2017;9: 39-45.

22. Nasehi B, Mortazavi A, Razavi SMA. Investigation on enthalpy changes in Iranian flat breads during storage. Iran Food Sci Technol Res J. 2005; 1(2). 65-72.

23. Demirkesen I, Sumnu G, Sahin S. Image analysis of gluten-free breads prepared with chestnut and rice flour and baked in different ovens. Food Bioprocess Technol. 2013; 6(7): 1749-1758.

24. AOAC. Official Method of Analysis, 17 th end. 2000; Association of Official Analytical Chemists Inc., Maryland

25. Sciarini LS, Ribotta PD, León AE, Pérez GT. Influence of gluten-free flours and their mixtures on batter properties and bread quality. Food Bioprocess Technol. 2010; 3(4), 577-585.

26. Elgeti D, Nordlohne SD, Föste M, Besl M, Linden MH, Heinz V, Becker T. Volume and texture improvement of gluten-free bread using quinoa white flour. J Cereal Sci.2014; 59(1), 41-47.

27. Sabanis D, Lebesi D, Tzia C. Effect of dietary fiber enrichment on selected properties of gluten-free bread. LWT-Food Sci Technol. 2009; 42(8): 1380-1389.

28. Koletta P, Irakli M, Papageorgiou M, Skendi A. Physicochemical and technological properties of highly enriched wheat breads with wholegrain non wheat flours. J Cereal sci. 2014; 60(3): 561-568.

29. Kadan RS, Robinson MG, Thibodeaux DP, Pepperman AB. Texture and other physicochemical properties of whole rice bread. J Food Sci. 2001; 66(7): 940-944.

30. Akbarian M, Koocheki A, Mohebbi M, Milani E. Rheological properties and bread quality of frozen sweet dough with added xanthan and different freezing rate. J Food Sci Technol. 2016;53(10),3761-769.

31. Das L, Raychaudhuri U, Chakraborty R. Effects of hydrocolloids as texture improver in coriander bread. J Food Sci Technol. 2015; 52(6): 3671-3680.

32. Farrera-Rebollo RR, dela Paz Salgado-Cruz M, Chanona-Pérez J, Gutiérrez-López GF, AlamillaBeltrán L, Calderón-Domínguez G. Evaluation of image analysis tools for characterization of sweet bread crumb structure. Food Bioprocess Technol. 2012; 5(2): 474-484.

33. Stikic R, Glamoclija Dj, Demin M, Vucelic-Radovic B, Jovanovic Z, Milojkovic-Opsenica D, Jacobsen S.E, Milovanovic M. Agronomical and nutritional evaluation of quinoaseeds (Chenopodium quinoa Willd.) as an ingredient in bread formulations. J Cereal Sci. 2012; 55(2): 132-138.

34. Jancurová M, Minarovicová L, Dandar A. Quinoa-a review. Czech J Food Sci. 2009; 27(2): 71-79.

35. Iglesias-Puig E, Haros M. Evaluation of performance of dough and bread incorporating chia (Salvia hispanica L.). Eur Food Res Technol. 2013; 237(6): 865-874. 